\title{
Investigation of blood groups in benign thyroid diseases in Turkey
}

\author{
Murat Dağdeviren ${ }^{1)}$, İhsan Ateş ${ }^{2}$, Burak Furkan Demir ${ }^{2)}$, Emine Ergün ${ }^{3)}$, Canan Yıldız ${ }^{3)}$ and \\ Mustafa Altay ${ }^{1)}$ \\ 1) Department of Endocrinology and Metabolism, University of Health Science, Keçiören Health Administration and Research Center, \\ Ankara, Turkey \\ 2) Department of Internal Medicine, University of Health Science, Ankara Numune Health Administration and Research Center, \\ Ankara, Turkey \\ 3) Department of Internal Medicine, University of Health Science, Keçiören Health Administration and Research Center, Ankara, \\ Turkey
}

\begin{abstract}
It is known that there is a relationship between some diseases and blood groups. The objective of our study is to investigate how often $\mathrm{ABO}$ and $\mathrm{Rh}$ blood groups are seen in benign thyroid diseases, especially in autoimmune-mediated thyroid diseases, and hence whether there is an association between blood groups and thyroid diseases. A total of 958 patients who were followed due to any benign thyroid disease were included in the study. The study population comprised 958 patients, 550 with Hashimoto's hypothyroidism, 160 with non-Hashimoto's hypothyroidism, 103 with iatrogenic hypothyroidism, 93 with central hypothyroidism, and 28 with Graves' and 24 with non-Graves' hyperthyroidism. Of the patients, $47.1 \%$ belonged to the $\mathrm{O}$ blood group, $30 \%$ to the A blood group, $15.2 \%$ to the $\mathrm{B}$ blood group, and $7.7 \%$ to the $\mathrm{AB}$ blood group while $90 \%$ were Rh-positive. The ratio of those with the $\mathrm{O}$ blood group was determined to be significantly higher in the Hashimoto's hypothyroidism group compared to the other disease groups. In the non-Hashimoto's hypothyroidism group, however, the ratio of the $\mathrm{AB}$ blood group was statistically significantly higher. While autoimmune diseases were more common in those with the $\mathrm{O}$ blood group, they were significantly lower in the $\mathrm{AB}$ blood group $(p<0.001)$. In our study, we determined that the ratio of the $\mathrm{O}$ blood group was significantly higher among patients with hypothyroidism due to Hashimoto's thyroiditis. These findings imply that there might be a relation between $\mathrm{O}$ blood group and Hashimoto's thyroiditis.
\end{abstract}

Key words: ABO, Blood groups, Hashimoto, Thyroid

\begin{abstract}
ABO BLOOD GROUPS were first defined by Landsteiner in 1901 [1]. A, B, and Rhesus (Rh) antigens are major antigens of the human blood group system [2]. These antigens are of primary importance in blood transfusions and organ transplantations [1]. They are present especially on the surface of red blood cells and on some different epithelial cells [3]. The ABO gene localized on chromosome 9q34 encodes glycosyltransferases, which catalyze nucleotide transfer to the $\mathrm{H}$ antigen; hence, ABO blood group antigens with a glycoprotein structure are formed $[3,4]$. The most common two blood groups are the $\mathrm{A}$ and $\mathrm{O}$ blood groups in both Turkey and the world. In several studies from Turkey, it has been

Submitted Jan. 7, 2019; Accepted Jun. 21, 2019 as EJ18-0582 Released online in J-STAGE as advance publication Jul. 12, 2019 Correspondence to: Murat Dağdeviren, Keçiören Training and Research Hospital, Department of Endocrinology and Metabolism, Pınarbaşı Mah., Sanatoryum Caddesi, Ardahan Sokak D:25, 06280 Keçiören/Ankara, Turkey.

E-mail: muratdagdeviren61@hotmail.com
\end{abstract}

observed that the most common blood group is A (36.38-44.8\%), followed by, in order, the $\mathrm{O}$ (30.65$35.09 \%)$, B (15.9-21.25\%), and AB (6.98-9.2\%) blood groups [5-11].

In previous studies, the ABO blood group system has been revealed to be associated with several types of cancer, primarily stomach, breast, and pancreas, as well as cardiovascular diseases, type 2 diabetes mellitus, infections, gastroduodenal ulcers, and several benign and malignant diseases including some rheumatologic and autoimmune diseases [1-3, 5, 12-14]. There are studies demonstrating that there might be an association between differentiated and medullary thyroid cancers among thyroid diseases $[15,16]$. Additionally, it has been demonstrated that there might be an association between blood groups and thyroid volume [17]. Again, the association of blood groups and autoimmune diseases, which has recently emerged, is extremely salient. All these findings suggest that there may also be an association between extremely commonly seen benign thyroid diseases, espe- 


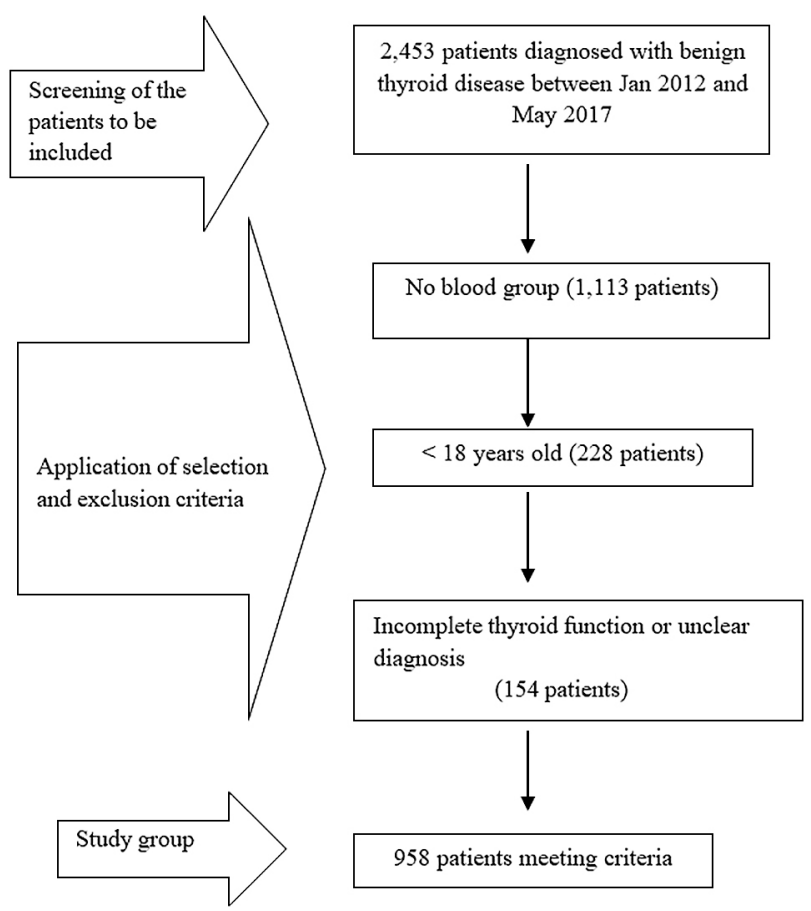

Fig. 1 Determination of patient groups

cially Hashimoto's thyroiditis, which is the most commonly seen thyroid disease and one of the autoimmune diseases, and blood groups. However, there is no study showing an association between these diseases and blood groups.

The objective of our study is to investigate how often $\mathrm{ABO}$ and $\mathrm{Rh}$ blood groups are seen in benign thyroid diseases, especially in autoimmune-mediated thyroid diseases, and hence whether there is an association between blood groups and thyroid diseases.

\section{Materials and Methods}

This study was conducted in a retrospective manner with patients who were followed in outpatient clinics due to any diagnosed benign thyroid disease in Kecioren Training and Research Hospital (TRH) and Ankara Numune TRH between January 2012 and May 2017.

A total of 2,453 patients were reached in the retrospective screening. Of those, 958 patients were included in the study, since they were $\geq 18$ years of age and their data were complete. The remaining 1,495 patients were excluded from the study because their blood group or thyroid function test results were absent (Fig. 1).

Patients' ages, sexes, blood groups, diagnoses, status of medication use, presence and number of thyroid nodules, and, if tested, presence of thyroid autoantibodies were recorded from the hospital automation systems and the patients' files. The patients were divided into 6 groups according to thyroid functions and etiological causes. Of the patients with positive anti-thyroglobulin (anti-Tg) and/or anti-thyroid peroxidase (anti-TPO) values, findings consistent with chronic autoimmune thyroiditis on thyroid ultrasonography (USG) (such as thyroid parenchyma that was heterogeneous and hypoechoic or included septations or pseudo-nodules), the patients with laboratory evaluations consistent with obvious or subclinical hypothyroidism constituted the Hashimoto's hypothyroidism group. Patients with obvious or subclinical primary hypothyroidism due to causes other than Hashimoto's disease (such as iodine deficiency, postradioactive iodine ablation hypothyroidism, postthyroiditis hypothyroidism, thyroid dysgenesis, etc.), whose USG findings and antibody levels were not consistent with chronic autoimmune thyroiditis, formed the non-Hashimoto's hypothyroidism group. Patients with hypothyroidism caused by a thyroid surgery performed for any reason constituted the iatrogenic hypothyroidism group. Patients with hypothyroidism due to hypophyseal thyroid-stimulating hormone (TSH) deficiency formed the central hypothyroidism group. Patients with hyperthyroidism with positive thyroid receptor antibody (TRAB), whose thyroid USG, Doppler, and scintigraphic imaging and iodine-131 uptake values were consistent with diffuse toxic goiter, formed the Graves' group. Patients with hyperthyroidism due to causes other than Graves' diseases, such as toxic adenoma and toxic multinodular goiter, formed the non-Graves' hyperthyroidism group.

When the patients were classified according to the autoimmune etiology, while the Hashimoto's hypothyroidism and Graves' groups constituted the autoimmune disease group, other diseases constituted the nonautoimmune disease group.

Those who were being followed for a period shorter than six months, who did not have a definitive diagnosis regarding etiology, whose thyroid biopsy results were malignant, who had moderate- or high-risk ultrasonographic imaging findings in accordance with the 2015 American Thyroid Association (ATA) guidelines, or who were under 18 years of age were not included in the study.

Approval from the relevant hospital ethics committee was received for this study.

\section{Statistical analysis}

Statistical evaluation was performed by using SPSS 20 for Windows (IBM SPSS Inc., Armonk, NY, USA). Normal distribution of the data was evaluated using the Kolmogorov-Smirnov test. Among numerical variables, those exhibiting normal distribution were represented as mean \pm standard deviation. Categorical variables were 
Table 1 Distribution of demographical and clinical findings by diseases

\begin{tabular}{|c|c|c|c|c|c|c|c|}
\hline Variables & $\begin{array}{c}\text { Hashimoto's } \\
\text { hypothyroidism } \\
n=550\end{array}$ & $\begin{array}{c}\text { Non-Hashimoto's } \\
\text { hypothyroidism } \\
n=160\end{array}$ & $\begin{array}{c}\text { Iatrogenic } \\
\text { hypothyroidism } \\
n=103\end{array}$ & $\begin{array}{c}\text { Central } \\
\text { hypothyroidism } \\
n=93\end{array}$ & $\begin{array}{l}\text { Graves } \\
n=28\end{array}$ & $\begin{array}{c}\text { Non-Graves } \\
\text { hyperthyroidism } \\
n=24\end{array}$ & $p$ \\
\hline \multicolumn{8}{|l|}{ Gender } \\
\hline Female & $452(82.2)$ & 139 (86.9) & $72(69.9)$ & $61(65.6)$ & $22(78.6)$ & $18(75.0)$ & \multirow{2}{*}{$<0.001^{*}$} \\
\hline Male & $98(17.8)$ & $21(13.1)$ & $31(30.1)$ & $32(34.4)$ & $6(21.4)$ & $6(25.0)$ & \\
\hline Age & $51.3 \pm 17.3$ & $54.5 \pm 15.5$ & $52.6 \pm 15.6$ & $49.5 \pm 16.3$ & $45.5 \pm 15.7$ & $45.3 \pm 15.4$ & 0.072 \\
\hline \multicolumn{8}{|l|}{ Nodule } \\
\hline No & $472(85.8)$ & $84(52.5)$ & $84(81.6)$ & $82(88.2)$ & $17(60.7)$ & $15(62.5)$ & \multirow{2}{*}{$<0.001^{*}$} \\
\hline Yes & $78(14.2)$ & $76(47.5)$ & $19(18.4)$ & $11(11.8)$ & $11(39.3)$ & $9(37.5)$ & \\
\hline \multicolumn{8}{|l|}{ Blood Group } \\
\hline $\mathrm{O}$ & $323(58.7)$ & $55(34.4)$ & $32(31.1)$ & $29(31.2)$ & $8(28.6)$ & $4(16.7)$ & \multirow{4}{*}{$<0.001 *$} \\
\hline A & $138(25.1)$ & $33(20.6)$ & $51(49.5)$ & $41(44.1)$ & $13(46.4)$ & $11(45.8)$ & \\
\hline B & $77(14.0)$ & $28(17.5)$ & $15(14.6)$ & $14(15.1)$ & $6(21.4)$ & $6(25.0)$ & \\
\hline $\mathrm{AB}$ & $12(2.2)$ & $44(27.5)$ & $5(4.9)$ & $9(9.7)$ & $1(3.6)$ & $3(12.5)$ & \\
\hline \multicolumn{8}{|l|}{$\mathrm{Rh}$} \\
\hline Negative & $49(8.9)$ & $14(8.8)$ & $18(17.5)$ & $13(14.0)$ & $2(7.1)$ & - & \multirow{2}{*}{$0.043 *$} \\
\hline Positive & $501(91.1)$ & $146(91.3)$ & $85(82.5)$ & $80(86.0)$ & $26(92.9)$ & $24(100.0)$ & \\
\hline \multicolumn{8}{|l|}{ Anti-TG } \\
\hline Negative & $70(12.7)$ & $160(100.0)$ & $103(100.0)$ & $93(100.0)$ & $14(50.0)$ & $15(62.5)$ & \multirow{2}{*}{$<0.001^{*}$} \\
\hline Positive & $480(87.3)$ & - & - & - & $14(50.0)$ & $9(37.5)$ & \\
\hline \multicolumn{8}{|l|}{ Anti-TPO } \\
\hline Negative & $123(22.4)$ & $159(99.4)$ & $103(100.0)$ & $90(96.8)$ & $13(46.4)$ & $18(75.0)$ & \multirow{2}{*}{$<0.001^{*}$} \\
\hline Positive & 427 (77.6) & $1(0.6)$ & - & $3(3.2)$ & $15(53.6)$ & $6(25.0)$ & \\
\hline \multicolumn{8}{|l|}{ Trab } \\
\hline Negative & $550(100.0)$ & $160(100.0)$ & $103(100.0)$ & $93(100.0)$ & $4(14.3)$ & $24(100.0)$ & \multirow{2}{*}{$<0.001^{*}$} \\
\hline Positive & - & - & - & - & $24(85.7)$ & - & \\
\hline \multicolumn{8}{|l|}{ Medication } \\
\hline No & $219(39.8)$ & $32(20.0)$ & $34(33.0)$ & $5(5.4)$ & $2(7.1)$ & $4(16.7)$ & \multirow{3}{*}{$<0.001^{*}$} \\
\hline LT4 & $331(60.2)$ & $128(80.0)$ & $69(67.0)$ & 88 (94.6) & $2(7.1)$ & - & \\
\hline Antithyroid & - & - & - & - & $24(85.7)$ & $20(83.3)$ & \\
\hline
\end{tabular}

Anti-Tg, Anti-Thyroglobulin Antibody; Anti-TPO, Antithyroid Peroxidase Antibody; Trab, Thyroid Receptor Antibody; LT4, levothyroxin

represented as count and percentage. For determination of numerical variables that differed between two groups, the Student $t$-test was used. For determination of numerical variables that differed between 3 and more groups, ANOVA testing was used. For comparison of categorical data, chi-square and Fisher exact chi-square tests were used. Potential confounding factors (age, gender, nodule, anti-TPO, anti-TG and medication) were adjusted with logistic regression when evaluating the risk probabilities of blood groups for Hashimoto's hypothyroidism.

In statistical analyses, $p<0.05$ was considered to be significant.

\section{Results}

The study population comprised 958 patients, 550
(57.4\%) with Hashimoto's hypothyroidism, 160 (16.7\%) with non-Hashimoto's hypothyroidism, 103 (9.7\%) with iatrogenic hypothyroidism, 93 (9.7\%) with central hypothyroidism, and 28 (2.9\%) with Graves' and 24 (2.5\%) with non-Graves' hyperthyroidism. When the patients were evaluated according to thyroid functions, 906 (94.6\%) had hypothyroidism and 52 (5.4\%) had hyperthyroidism, while $578(60.3 \%)$ had an autoimmunemediated thyroid disease (Graves' or Hashimoto's thyroiditis). Of the total patient group, $79.7 \%$ were female. Mean age was $51.5 \pm 16.8$ years. Of the patients, $47.1 \%$ belonged to the O blood group, 30\% the A blood group, $15.2 \%$ the B blood group, and $7.7 \%$ the $\mathrm{AB}$ blood group while 90\% were Rh-positive. Furthermore, 204 patients had nodules. The distribution of demographical and clinical findings by diseases is given in Table 1 . 
Among patients with Hashimoto's hypothyroidism and non-Hashimoto's hypothyroidism, the most common blood group was $\mathrm{O}$, and in other patients the most common one was A. The ratio of those with the $\mathrm{O}$ blood group was determined to be significantly higher in the Hashimoto's hypothyroidism group compared to the other disease groups. In the non-Hashimoto's hypothyroidism group, however, the ratio of the AB blood group was statistically significantly higher $(p<0.001)$. All of the patients with non-Graves' hyperthyroidism were $\mathrm{Rh}+$. The ratio of $\mathrm{Rh}+$ patients was higher in the Hashimoto's hypothyroidism, non-Hashimoto's hypothyroidism, and Graves' patient groups compared to those in the iatrogenic hypothyroidism and central hypothyroidism groups $(p=0.04)$ (Table 1).

When the patients were classified by blood groups, the ratio of males was determined to be higher in the $\mathrm{O}$ blood group compared to other blood groups $(p=0.004)$. Age did not show any difference in regard to blood groups $(p=0.2)$. While the most common disease was Hashimoto's hypothyroidism among the O, A, and B blood groups, in the $\mathrm{AB}$ blood group, the most common disease was non-Hashimoto's hypothyroidism $(p<$ 0.001). The distribution of demographical and clinical findings by blood groups is given in Table 2 .

While autoimmune diseases were more common in those with the $\mathrm{O}$ blood group, they were significantly lower in the AB blood group ( $p<0.001)$. There was no significant association between autoimmune thyroid diseases and Rh groups $(p>0.05)$ (Table 3$)$.

In the logistic regression analysis conducted by taking O blood group as reference, it was detected that A, B and AB blood groups had lower risk factors of Hashimoto's thyroiditis. Furthermore, a similar result was obtained in the adjusted model to which potential confounding factors (age, gender, nodule, anti-TPO, anti-TG and medication) were included (Table 4).

There was no association of presence of nodules with age, sex, or ABO and Rh groups $(p>0.05)$.

\section{Discussion}

In our study, we determined that the ratio of the $\mathrm{O}$ blood group was significantly higher among patients with hypothyroidism due to Hashimoto's thyroiditis. In addition to this, the ratio of the AB blood group was significantly lower among patients with autoimmune thyroid diseases (both Hashimoto's thyroiditis and Graves' disease). The frequency of the presence of the Rh antigen was determined to be similar in patients with and without an autoimmune thyroid disease. No association was determined between the presence of nodules and $\mathrm{ABO}$ and $\mathrm{Rh}$ blood groups.
The association between blood groups and various diseases has been a topic of interest for many years since Aird et al. revealed the association between the A blood group and gastric cancer in 1953 [18]. The opinion that there might be an association between malignant diseases and blood groups has aroused particular interest and studies on many different organ malignancies have been conducted for many years. One of these organs is the thyroid gland, which is an endocrine organ. Different results have been obtained in a small number of studies on differentiated malignancies of the thyroid. While Vasan et al. could not determine any association between thyroid cancers and blood groups in their study, Gong et al. determined in their study that there was lower risk of thyroid cancer in patients with the A blood group compared to the $\mathrm{O}$ blood group and, again, in those with nonB blood groups compared to the B blood group [19, 20]. There are also studies that investigated the association of medullary and anaplastic thyroid cancers with blood groups [16, 21].

Recently, the number of studies investigating the association of benign diseases with blood groups, in addition to malignancies, has also been increasing. Autoimmune and rheumatologic diseases constitute an important group among these diseases. In previous studies, it was revealed that many autoimmune diseases such as multiple sclerosis, celiac disease, rheumatoid arthritis, and alopecia areata may be associated with blood groups [14, $22,23]$. However, the pathogenesis in this association has not been established. In some studies, it was demonstrated that $\mathrm{ABO}$ blood group antigens might be associated with general inflammatory response and singlenucleotide polymorphisms in the ABO locus may increase TNF- $\alpha$ and soluble intercellular adhesion molecule-1 (ICAM-1) levels [14, 24-27]. Again, in some studies, it was determined that there was an association between HLA antigens and ABO blood groups [22, 23].

Hashimoto's thyroiditis (chronic autoimmune thyroiditis) is a chronic disease caused by autoimmunemediated destruction of the thyroid gland. It is the most commonly seen thyroid disease and 7-fold more frequent among women. B cells (some antibodies, primarily anti$\mathrm{Tg}$ and anti-TPO), T cells (various cytokines), and HLA antigens (such as HLA-DR variant DR $\beta 1-A r g 74)$ play a role in the development of the disease [27, 28]. Studies that investigated the association between autoimmune diseases and blood groups suggested that there may be a similar association in Hashimoto's thyroiditis as well. In our study, in contrast to the blood group distribution in the general Turkish population, the $\mathrm{O}$ blood group was determined to be the most common one among patients with Hashimoto's thyroiditis. Furthermore, the ratio of the $\mathrm{O}$ blood group among these patients was significantly 
Table 2 Distribution of demographical and clinical findings by blood groups

\begin{tabular}{|c|c|c|c|c|c|}
\hline \multirow[b]{2}{*}{ Variables } & \multicolumn{4}{|c|}{ Blood Groups } & \multirow[b]{2}{*}{$p$} \\
\hline & $\begin{array}{c}\mathrm{O} \\
n=451\end{array}$ & $\begin{array}{c}\text { A } \\
n=287\end{array}$ & $\begin{array}{c}\text { B } \\
n=146\end{array}$ & $\begin{array}{c}\mathrm{AB} \\
n=74\end{array}$ & \\
\hline \multicolumn{6}{|l|}{ Gender } \\
\hline Female & $338(74.9)$ & $245(85.4)$ & $118(80.8)$ & $63(85.1)$ & \multirow{2}{*}{$0.004 *$} \\
\hline Male & $113(25.1)$ & $42(14.6)$ & $28(19.2)$ & $11(14.9)$ & \\
\hline Age & $51.0 \pm 17.0$ & $53.0 \pm 15.5$ & $49.5 \pm 15.7$ & $52.6 \pm 17.8$ & 0.156 \\
\hline \multicolumn{6}{|l|}{ Disease } \\
\hline Hashimoto's hypothyroidism & $323(71.6)$ & $138(48.1)$ & $77(52.7)$ & $12(16.2)$ & \multirow{6}{*}{$<0.001 *$} \\
\hline Non-Hashimoto's hypothyroidism & $55(12.2)$ & $33(11.5)$ & $28(19.2)$ & $44(59.5)$ & \\
\hline Iatrogenic hypothyroidism & $32(7.1)$ & $51(17.8)$ & $15(10.3)$ & $5(6.8)$ & \\
\hline Central hypothyroidism & $29(6.4)$ & $41(14.3)$ & $14(9.6)$ & $9(12.2)$ & \\
\hline Graves & $8(1.8)$ & $13(4.5)$ & $6(4.1)$ & $1(1.4)$ & \\
\hline Non-Graves hyperthyroidism & $4(0.9)$ & $11(3.8)$ & $6(4.1)$ & $3(4.1)$ & \\
\hline \multicolumn{6}{|l|}{ Autoimmunity } \\
\hline Autoimmune & $331(73.4)$ & $151(52.6)$ & $83(56.8)$ & $13(17.6)$ & \multirow{2}{*}{$<0.001 *$} \\
\hline Non-autoimmune & $120(26.6)$ & $136(47.4)$ & $63(43.2)$ & $61(82.4)$ & \\
\hline \multicolumn{6}{|l|}{ Thyroid functions } \\
\hline Hypothyroidism & $439(97.3)$ & $263(91.6)$ & $134(91.8)$ & $70(94.6)$ & \multirow{2}{*}{$0.002 *$} \\
\hline Hyperthyroidism & $12(2.7)$ & $24(8.4)$ & $12(8.2)$ & $4(5.4)$ & \\
\hline \multicolumn{6}{|l|}{ Nodule } \\
\hline No & $359(79.6)$ & $226(78.7)$ & $113(77.4)$ & $56(75.7)$ & \multirow{2}{*}{0.833} \\
\hline Yes & $92(20.4)$ & $61(21.3)$ & $33(22.6)$ & $18(24.3)$ & \\
\hline \multicolumn{6}{|l|}{$\mathrm{Rh}$} \\
\hline Negative & $35(7.8)$ & $41(14.3)$ & $11(7.5)$ & $9(12.2)$ & \multirow{2}{*}{$0.023^{*}$} \\
\hline Positive & $416(92.2)$ & $246(85.7)$ & $135(92.5)$ & $65(87.8)$ & \\
\hline \multicolumn{6}{|l|}{ Anti-TG } \\
\hline Negative & 177 (39.2) & $139(48.4)$ & $78(53.4)$ & $61(82.4)$ & \multirow{2}{*}{$<0.001 *$} \\
\hline Positive & $274(60.8)$ & $148(51.6)$ & $68(46.6)$ & 13 (17.6) & \\
\hline \multicolumn{6}{|l|}{ Anti-TPO } \\
\hline Negative & $210(46.6)$ & $143(49.8)$ & $91(62.3)$ & $62(83.8)$ & \multirow{2}{*}{$<0.001 *$} \\
\hline Positive & $241(53.4)$ & $144(50.2)$ & $55(37.7)$ & $12(16.2)$ & \\
\hline \multicolumn{6}{|l|}{ Trab } \\
\hline Negative & $443(98.2)$ & $276(96.2)$ & $142(97.3)$ & $73(98.6)$ & \multirow{2}{*}{0.336} \\
\hline Positive & $8(1.8)$ & $11(3.8)$ & $4(2.7)$ & $1(1.4)$ & \\
\hline \multicolumn{6}{|l|}{ Medication } \\
\hline No & 179 (39.7) & $51(17.8)$ & $45(30.8)$ & $21(28.4)$ & \multirow{3}{*}{$<0.001 *$} \\
\hline LT4 & $262(58.1)$ & $216(75.3)$ & $91(62.3)$ & $49(66.2)$ & \\
\hline Antithyroid & $10(2.2)$ & $20(7.0)$ & $10(6.8)$ & $4(5.4)$ & \\
\hline
\end{tabular}

Anti-Tg, Anti-Thyroglobulin Antibody; Anti-TPO, Antithyroid Peroxidase Antibody; Trab, Thyroid Receptor Antibodyl; LT4, levothyroxin

higher compared to the other disease groups. These findings imply that there might be a relation between $\mathrm{O}$ blood group and Hashimoto's thyroiditis. This situation was not observed in patients with Graves' disease, which is another autoimmune thyroid disease. However, the number of patients with Graves' disease in our study was 
Table 3 Distribution of demographical and clinical findings by blood groups by autoimmune groups

\begin{tabular}{|c|c|c|c|}
\hline Variables & $\begin{array}{c}\text { Autoimmune } \\
n=578\end{array}$ & $\begin{array}{c}\text { Non-autoimmune } \\
\quad n=380\end{array}$ & $p$ \\
\hline \multicolumn{4}{|l|}{ Gender } \\
\hline Female & $474(82.0)$ & $290(76.3)$ & \multirow{2}{*}{$0.032 *$} \\
\hline Male & $104(18.0)$ & $90(23.7)$ & \\
\hline Age & $51.2 \pm 17.3$ & $52.2 \pm 16.1$ & 0.274 \\
\hline \multicolumn{4}{|l|}{ Disease } \\
\hline Hashimoto's hypothyroidism & $550(95.2)$ & - & \multirow{6}{*}{ - } \\
\hline Non-Hashimoto's hypothyroidism & - & $160(42.1)$ & \\
\hline Iatrogenic hypothyroidism & - & $103(27.1)$ & \\
\hline Central hypothyroidism & - & $93(24.5)$ & \\
\hline Graves & $28(4.8)$ & $0(0.0)$ & \\
\hline Non-Graves hyperthyroidism & - & $24(6.3)$ & \\
\hline \multicolumn{4}{|l|}{ Thyroid functions } \\
\hline Hypothyroidism & $550(95.2)$ & $356(93.7)$ & \multirow{2}{*}{0.382} \\
\hline Hyperthyroidism & $28(4.8)$ & $24(6.3)$ & \\
\hline \multicolumn{4}{|l|}{ Nodule } \\
\hline No & $489(84.6)$ & $265(69.7)$ & \multirow{2}{*}{$<0.001^{*}$} \\
\hline Yes & $89(15.4)$ & $115(30.3)$ & \\
\hline \multicolumn{4}{|l|}{ Blood group } \\
\hline $\mathrm{O}$ & $331(57.3)$ & $120(31.6)$ & \multirow{4}{*}{$<0.001 *$} \\
\hline A & $151(26.1)$ & $136(35.8)$ & \\
\hline $\mathrm{B}$ & $83(14.4)$ & $63(16.6)$ & \\
\hline $\mathrm{AB}$ & $13(2.2)$ & $61(16.1)$ & \\
\hline \multicolumn{4}{|l|}{$\mathrm{Rh}$} \\
\hline Negative & $51(8.8)$ & $45(11.8)$ & \multirow{2}{*}{0.128} \\
\hline Positive & $527(91.2)$ & $335(88.2)$ & \\
\hline \multicolumn{4}{|l|}{ Anti-TG } \\
\hline Negative & $84(14.5)$ & 371 (97.6) & \multirow{2}{*}{$<0.001 *$} \\
\hline Positive & $494(85.5)$ & $9(2.4)$ & \\
\hline \multicolumn{4}{|l|}{ Anti-TPO } \\
\hline Negative & $136(23.5)$ & $370(97.4)$ & \multirow{2}{*}{$<0.001^{*}$} \\
\hline Positive & $442(76.5)$ & $10(2.6)$ & \\
\hline \multicolumn{4}{|l|}{ Trab } \\
\hline Negative & $554(95.8)$ & $380(100.0)$ & \multirow{2}{*}{$<0.001 *$} \\
\hline Positive & $24(4.2)$ & - & \\
\hline \multicolumn{4}{|l|}{ Medication } \\
\hline No & $221(38.2)$ & 75 (19.7) & \multirow{3}{*}{$<0.001 *$} \\
\hline LT4 & $333(57.6)$ & $285(75.0)$ & \\
\hline Antithyroid & $24(4.2)$ & $20(5.3)$ & \\
\hline
\end{tabular}

Anti-Tg, Anti-Thyroglobulin Antibody; Anti-TPO, Antithyroid Peroxidase Antibody; Trab, Thyroid Receptor Antibody; LT4, levothyroxin

extremely low. In addition to this, the ratio of the $\mathrm{AB}$ blood group was significantly lower in both autoimmune thyroid diseases compared to other diseases. This finding also suggested that the risk of autoimmune thyroid disease may be lower in patients with the $\mathrm{AB}$ blood group. The frequency of the presence of the Rh antigen was 
Table 4 Risk factors according to blood groups in Hashimoto's hypothyroidism

\begin{tabular}{|c|c|c|c|c|c|c|}
\hline \multirow{2}{*}{ Blood Group } & \multicolumn{3}{|c|}{ Unadjusted Model } & \multicolumn{3}{|c|}{ Adjusted Model } \\
\hline & OR & $95 \% \mathrm{CI}$ & $p$ & OR & $95 \% \mathrm{CI}$ & $p$ \\
\hline $\mathrm{O}$ & ref & & & ref & & \\
\hline A & 0.37 & $0.27-0.50$ & $<0.001^{*}$ & 0.44 & $0.32-0.61$ & $<0.001^{*}$ \\
\hline B & 0.44 & $0.30-0.65$ & $<0.001 *$ & 0.49 & $0.32-0.73$ & $0.001 *$ \\
\hline \multirow[t]{2}{*}{$\mathrm{AB}$} & 0.08 & $0.04-0.15$ & $<0.001^{*}$ & 0.07 & $0.04-0.14$ & $<0.001^{*}$ \\
\hline & \multicolumn{3}{|c|}{ Nagelkerke $\mathrm{R}^{2}=0.198 ; p<0.001^{*}$} & \multicolumn{3}{|c|}{ Nagelkerke $\mathbf{R}^{2}=0.236 ; p<0.001 *$} \\
\hline
\end{tabular}

Adjusted Model: potential confounding factors (age, gender, nodule, anti-TPO, anti-TG and medication) were included.

OR, Odds ratio; CI, confidence intervals; ref, reference

determined to be similar in patients with and without an autoimmune thyroid disease. In some previous studies, it was shown that the ratio of the $\mathrm{O}$ blood group was higher in some autoimmune diseases such as familial Mediterranean fever, systemic lupus erythematosus, and systemic sclerosis [5]. However, there are also studies demonstrating no association between $\mathrm{ABO}$ blood groups and Behçet's disease and some autoimmune-mediated diseases such as pemphigus $[22,29]$. In a study by İslamoğlu and Unal, however, while there was no association between alopecia areata and $\mathrm{ABO}$ blood groups, a significant association was determined with Rhesus factor [14].

As individuals with the $\mathrm{O}$ blood group do not have $\mathrm{A}$ and $\mathrm{B}$ antigens, they have anti-A and anti-B antibodies that develop against them. In the AB blood group, however, these antibodies are absent, as these individuals have $\mathrm{A}$ and $\mathrm{B}$ antigens [30]. The fact that the ratio of autoimmune thyroid diseases is high in the $\mathrm{O}$ blood group, in which both antibodies formed against the blood group antigens are present, and that these ratios are low in the $\mathrm{AB}$ blood group, in which these antibodies are absent, supports the view that there may be an association between blood group antigens and antibodies and these diseases. Although there is no clear evidence yet revealing this association, some researchers defined a staining pattern similar to anti-A and anti-B blood group antibodies, as well as to intercellular substance in patients with pemphigus $[31,32]$. However, the predominant view here is that $\mathrm{A}$ and $\mathrm{B}$ antibodies generate a pemphigus antibody-like pseudo-staining pattern, rather than an immunological activity. Nevertheless, the fact that Hashimoto's thyroiditis was more commonly seen in patients with $\mathrm{A}$ and $\mathrm{B}$ antibodies in our study and less commonly seen in those without A and B antibodies reveals a need for further studies in order to clarify this issue.

Thyroid nodules are lesions whose frequency varies between $19 \%$ and $68 \%$ in different studies; in other words, they are extremely common, and $5 \%-15 \%$ of them are malignant $[33,34]$. While some studies have tried to reveal an association between malignant nodules and blood groups, the situation with benign nodules remains unknown. In our study, all nodules were of a benign character (nodules whose biopsy results were benign or those without biopsy indication in accordance with ATA guidelines). It was determined that there was no difference between cases with and without a thyroid nodule in regard to $\mathrm{ABO}$ and $\mathrm{Rh}$ blood groups.

In our study, blood group distribution differed from the general Turkish population in patients with benign thyroid diseases. While the blood group distribution is $\mathrm{A}$ $>\mathrm{O}>\mathrm{B}>\mathrm{AB}$ in Turkey as a whole, it was found to be $\mathrm{O}$ $>\mathrm{A}>\mathrm{B}>\mathrm{AB}$ in our population [5-11]. The most important reason for this was that a substantial portion of our population comprised patients with Hashimoto's thyroiditis and there was a high ratio of the $\mathrm{O}$ blood group among these patients.

Our study had some limitations. First, this study was conducted retrospectively in a file-screening manner. Only the patients who were followed in two centers were included in the study. Thus, it may be thought that the obtained data might not reflect the general population. However, although not reflecting nationwide data, findings supporting the hypothesis that we established were obtained. The lack of a control group may also be considered as a limiting factor of our study. However, the ratios obtained through evaluation of distributions of blood groups in the patient groups were interpreted by comparing them with each other and with the blood group distributions of the Turkish population as a whole, as obtained from previous studies.

In conclusion, the fact that blood group distributions may be different in benign thyroid diseases from the general population and also different among disease groups has been demonstrated for the first time. It was determined that the ratio of the $\mathrm{O}$ blood group was significantly higher especially in patients with Hashimoto's 
thyroiditis, and the ratio of the $\mathrm{AB}$ blood group was lower in both patients with Hashimoto's thyroiditis and those with Graves' disease. However, more extensive clinical and experimental studies are needed in order to reveal these associations more clearly and, if there is an association, to clarify the mechanisms.

\section{Disclosure}

All authors had no conflict of interest regarding this manuscript.

\section{References}

1. Zhang H, Mooney CJ, Reilly MP (2012) ABO blood groups and cardiovascular diseases. Int J Vasc Med 2012: 641917.

2. Meo SA, Rouq FA, Suraya F, Zaidi SZ (2016) Association of $\mathrm{ABO}$ and $\mathrm{Rh}$ blood groups with type 2 diabetes mellitus. Eur Rev Med Pharmacol Sci 20: 237-242.

3. Park S, Kim KS, Kim JS, Han W, Park BW, et al. (2017) Prognostic value of $\mathrm{ABO}$ blood types in young patients with breast cancer; a nationwide study in Korean Breast Cancer Society. Med Oncol 34: 118.

4. Yazer MH (2005) What a difference 2 nucleotides make: a short review of ABO genetics. Transfus Med Rev 19: 200 209.

5. Çildağ S, Kara Y, Şentürk T (2017) ABO blood groups and rheumatic diseases. Eur J Rheumatol 4: 250-253.

6. Guyton AC, Hall JE (2006) Blood types; transfusion; tissue and organ transplantation. In: Guyton AC, Hall JE (ed) Textbook of Medical Physiology (11th) Philadelphia, USA: 452-453.

7. Doğan E, Sevimligül G, Çelik C, Şencan M (2015) Blood group distribution of donors and patients admitted to the Blood and Transfusion Center of Cumhuriyet University Hospital. CMJ 37: 23-29.

8. Salduz ZIY, Çetin G, Karatoprak C, Ozder A, Bilginç M, et al. (2015) $\mathrm{ABO}$ and $\mathrm{Rh}$ blood group distribution in İstanbul province (Turkey). İstanbul Med J 16: 98-100.

9. Balc1 Y, Ovet G, Covut İE, Goncu F, Y1lmaz M (2010) $\mathrm{ABO}$ and $\mathrm{Rh}$ blood groups frequency in Denizli province. UHOD 20: 103-105.

10. Temiz H, Altıntaş A, Gül K (2008) Distribution of ABO and Rh blood groups in Diyarbakır. UHOD 18: 234-237.

11. Dilek İ, Demir C, Bay A, Akdeniz H, Öner AF (2006) $\mathrm{ABO}$ and $\mathrm{Rh}$ blood groups frequency in men and women living in eastern Turkey. UHOD 16: 23-26.

12. Wolpin BM, Chan AT, Hartge P, Chanock SJ, Kraft P, et al. (2009) ABO blood group and the risk of pancreatic cancer. J Natl Cancer Inst 101: 424-431.

13. Panda AK, Panda SK, Sahu AN, Tripathy R, Ravindran B, et al. (2011) Association of ABO blood group with severe falciparum malaria in adults: case control study and metaanalysis. Malar J 10: 309.

14. İslamoğlu ZGK, Unal M (2018) Is there an association of $\mathrm{ABO}$ blood groups and Rhesus factor with alopecia areata? J Cosmet Dermatol 17: 1271-1274.

15. González-Cámpora R, García-Sanatana JA, Jordà i Heras MM, Salaverri CO, Vázquez-Ramírez FJ, et al. (1998)
Blood group antigens in differentiated thyroid neoplasms. Arch Pathol Lab Med 122: 957-965.

16. Vierbuchen M, Larena A, Schröder S, Hanisch FG, Ortmann M, et al. (1992) Blood group antigen expression in medullary carcinoma of the thyroid. An immunohistochemical study on the occurrence of type 1 chain-derived antigens. Virchows Arch B Cell Pathol Incl Mol Pathol 62: 79-88.

17. Turcios S, Lence-Anta JJ, Santana JL, Pereda CM, Velasco M, et al. (2015) Thyroid volume and its relation to anthropometric measures in a healthy Cuban population. Eur Thyroid J 4: 55-61.

18. Aird I, Bentall HH, Roberts JA (1953) A relationship between cancer of stomach and the ABO blood groups. $\mathrm{Br}$ Med J 1: 799-801.

19. Vasan SK, Hwang J, Rostgaard K, Nyren O, Ullum H, et al. (2016) ABO blood group and risk of cancer: a registerbased cohort study of 1.6 million blood donors. Cancer Epidemiol 44: 40-43.

20. Gong Y, Yang YS, Zhang XM, Su M, Wang J, et al. (2012) ABO blood type: diabetes and risk of gastrointestinal cancer in northern China. World J Gastroenterol 18: 563-569.

21. Zivaljevic V, Slijepcevic N, Paunovic I, Diklic A, Kalezic $\mathrm{N}$, et al. (2014) Risk factors for anaplastic thyroid cancer. Int $J$ Endocrinol 2014: 815070.

22. Valikhani M, Kavand S, Toosi S, Kavand G, Ghiasi M (2007) ABO blood groups, Rhesus factor and pemphigus. Indian J Dermatol 52: 176-178.

23. Eiermann TH, Vejbaesya S, Prestel H, Roepke A, MullerMyhsok B, et al. (2002) Association and linkage of human leukocyte antigens with psoriasis-revisited. Transfus Med Hemother 29: 326-330.

24. Paré G, Chasman DI, Kellogg M, Zee RY, Rifai N, et al. (2008) Novel association of ABO histo-blood group antigen with soluble ICAM-1: results of a genome-wide association study of 6,578 women. PLoS Genet 4: e1000118.

25. Melzer D, Perry JR, Hernandez D, Corsi AM, Stevens K, et al. (2008) A genome-wide association study identifies protein quantitative trait loci (pQTLs). PLoS Genet 4: e1000072.

26. Park EJ, Lee JH, Yu GY, He G, Ali SR, et al. (2010) Dietary and genetic obesity promote liver inflammation and tumorigenesis by enhancing IL-6 and TNF expression. Cell 140: 197-208.

27. Balázs C (2012) The role of hereditary and environmental 
factors in autoimmune thyroid diseases. Orv Hetil 153: 1013-1022 (In Hungarian).

28. Davies TF (2019) Pathogenesis of Hashimoto's thyroiditis (chronic autoimmune thyroiditis). UpToDate URL: https:// www.uptodate.com/contents/pathogenesis-of-hashimotosthyroiditis-chronic-autoimmune-thyroiditis?search= pathogenesis-of-hashimotos-thyroiditis-chronicautoimmunethyroiditis\&source $=$ search_result\&selected Title $=1 \sim 150 \&$ usage_type $=$ default\&display_rank $=1$.

29. Ozyurt K, Oztürk P, Gül M, Benderli YC, Cölgeçen E, et al. (2013) ABO blood groups, Rhesus factor, and Behcet's disease. Acta Dermatovenerol Alp Pannonica Adriat 22: 63-64.

30. Wolfram W, Sauerwein KM, Binder CJ, Eibl-Musil N, Wolf HM, et al. (2016) Pneumococcal polysaccharide vaccination elicits igg anti-a/B blood group antibodies in healthy individuals and patients with type 1 diabetes mellitus. Front Immunol 7: 493.

31. Grob PJ, Inderbitzin TM (1967) Pemphigus antigen and blood group substances A and B. J Invest Dermatol 49: 285-287.

32. Goldblatt F, Gordon TP (2002) Antibodies to blood group antigens mimic pemphigus staining patterns: a useful reminder. Autoimmunity 35: 93-96.

33. Guth S, Theune U, Aberle J, Galach A, Bamberger CM (2009) Very high prevalence of thyroid nodules detected by high frequency $(13 \mathrm{MHz})$ ultrasound examination. Eur J Clin Invest 39: 699-706.

34. Yi KH (2016) The revised 2016 Korean Thyroid Association guidelines for thyroid nodules and cancers: differences from the 2015 American Thyroid Association guidelines. Endocrinol Metab (Seoul) 31: 373-378. 